\title{
Comparison of Post-operative Bleeding Incidence in Laser Hemorrhoidoplasty with and without Hemorrhoidal Artery Ligation: A Double-Blinded Randomized Controlled Trial
}

Shu Yu Lim

University of Malaya: Universiti Malaya

Retnagowri Rajandram ( $\sim$ retnagowri@gmail.com )

University of Malaya: Universiti Malaya https://orcid.org/0000-0001-5247-2817

April Camilla Roslani

University of Malaya: Universiti Malaya https://orcid.org/0000-0003-2458-965X

\section{Research Article}

Keywords: Colorectal Surgery, Hemorrhoidal Artery Ligation, Hemorrhoids, Hemorrhoidectomy, Laser Hemorrhoidoplasty

Posted Date: February 23rd, 2022

DOI: https://doi.org/10.21203/rs.3.rs-1095466/v1

License: (c) (1) This work is licensed under a Creative Commons Attribution 4.0 International License.

Read Full License 


\section{Abstract}

\section{Purpose:}

To investigate the effectiveness of hemorrhoidal artery ligation supplementation in reducing the incidence of post laser hemorrhoidoplasty bleeding.

\section{Method:}

This was a double-blind, randomized controlled trial comparing post-operative bleeding incidence in patients undergoing laser hemorrhoidoplasty (LHP) only versus LHP with hemorrhoidal artery ligation (HAL). Outcome measures included post-operative bleeding and its severity (i.e. verbal rating scale and Clavien-Dindo classification), presence of perianal swelling and pain score (visual analog score) at 1-day, 1-week and 6-weeks post-operatively. Statistical tests were performed and a value of $\mathrm{P}<0.05$ was considered significant.

\section{Results:}

Seventy-six patients were randomized. There was no difference in median operating time. The bleeding incidence was highest at 1-week post-operatively (17.1\%), and decreased to $1.3 \%$ at 6 -weeks. There was no significant difference in bleeding incidence between both groups at any of the measured timepoints $(P>0.05)$. Severity of bleeding and incidence of post-operative perianal swelling were similar in both groups $(P>0.05)$. There was no difference in median pain scores.

\section{Conclusion:}

Supplementation of HAL to LHP does not reduce the post-operative bleeding incidence. LHP is sufficient as a stand-alone procedure for treating haemorrhoids.

\section{Trial Registration:}

National Registration Number is NMRR-15-1112-24065 (IIR). The trial start date was 1st January 2015 with the ClinicalTrials.gov identifier and registration number as NCT04667169.

\section{Background}

Symptomatic haemorrhoids have an estimated prevalence of $38.9 \%$ in adults [1]. These reported approximations do not include haemorrhoid sufferers who evade medical help and rely on over-thecounter medications [2,3]. Non-excisional hemorrhoidal procedures have been gaining popularity as a treatment for these symptomatic haemorrhoids as these procedures are significantly less painful as minimally invasive procedure [4-6]. Furthermore, post-operative complications and recurrence rates are comparatively low for non-excisional procedures [7]. 
Lasers such as Nd:YAG have been used to perform excisional hemorrhoidectomies [8]. On the other hand, Laser Hemorrhoidoplasty (LHP) utilizes diode lasers, in a non-excisional manner, and is associated with reduced post-operative pain. It is particularly useful for grade 1-2 haemorrhoids, where prolapse is less significant $[6,9]$. However, a relatively common complication is post-operative bleeding, with ClavienDindo Class III bleeding in the region of 1-5\% [10]. Theoretically, ligating the hemorrhoidal arteries in a manner similar to the Doppler-guided hemorrhoidal artery ligation (HAL) procedure, could reduce the incidence of post-operative bleeding. Moreover, HAL can be safely performed without Doppler guidance in order to save time [11]; as the number and location of branches of the superior hemorrhoidal arteries are relatively constant [12].

The incidence of bleeding and recurrence of prolapse haemorrhoids for LHP has not been well reported $[13]$ and can be high as $13 \%[14,15]$. While the incidence of postoperative bleeding for HAL without doppler guidance has lately been reported to be as low as $1 \%[16]$ range up to $70 \%[17,18]$. Theoretically, using HAL as an adjunct to LHP could reduce the incidence of bleeding, but this has not been formally assessed. We aimed to determine the effectiveness of HAL supplementation to LHP in reducing the incidence of postoperative bleeding. Post-operative pain, presence of perianal swelling and operating time associated with the two techniques were also evaluated.

\section{Methodology}

\section{STUDY DESIGN}

An interventional study is designed as a double-blinded randomized controlled trial to look into the postoperative bleeding incidence of patients undergoing LHP only versus LHP plus HAL at University of Malaya Medical Centre (UMMC) (Fig. 1). The study commenced in November 2016 and completed recruitment in October 2018.

\section{STUDY INTERVENTION}

LHP access for all patients was through stab incisions at the ano-cutaneous junction, followed by submucosal tunneling to the pedicle of the haemorrhoids with artery forceps. The laser catheter was introduced submucosally towards the pedicle guided by a visible beam to ascertain the exact location of the laser fiber. Ceralas D 50 Evolve Laser (Biolitec AG, Jena, Germany), a $980 \mathrm{~nm}$ diode laser, was used. Pulsed laser energy, each lasting 3 seconds, was subsequently delivered at $5 \mathrm{~mm}$ intervals, while gradually withdrawing the laser catheter. Patients in the HAL supplementation group underwent sutureligation (especially for dearterialization) of each identified pedicle without Doppler guidance. Here, 2 - 0 coated Vicryl Plus Violet $70 \mathrm{~cm}$ CT-2 (needle used) sutures (Ethicon) were employed. In all cases no more than one suture was required even if more than one hemorrhoidal column needed suture ligation. Postoperative analgesia was standardized to oral paracetamol $1 \mathrm{gm}$ six hourly, and oral celecoxib $200 \mathrm{mg} 12-$ hourly, for five days. Syrup Lactulose $15 \mathrm{~mL} 12$-hourly for one week to prevent constipation. Subjects were 
discharged at the discretion of the surgeon based on discharge criteria for post-operative bleeding (VRS) and its severity (Clavien-Dindo Classification), presence of perianal swelling and pain score (VAS).

Patients had general anaesthesia $(n=16)$ or regional anaesthesia $(n=60)$ and were blinded to the type of operative procedure. Of the patients on general anaesthesia, 10 were in the LHP group while 6 were LHP with HAL group. It was anticipated that method of anaesthesia would not affect the pain score at 24 hours post-operation, as the half-lives of either method would have been exceeded. Prophylactic antibiotics, comprising intravenous cefoperazone $2 \mathrm{gm}$ and intravenous metronidazole $500 \mathrm{mg}$, were given at induction. Intravenous Ciprofloxacin $400 \mathrm{mg}$ was used instead, if patients were allergic to the aforementioned antibiotics. Once the patients were anaesthetised, they were positioned in lithotomy. Randomization of the procedures was performed using sealed envelopes. Procedures were performed through an anoscope inserted into the anus. Two drugs used for Clavien-Dindo Grade II/III type complications were tranexamic acid and Daflon, which is a micronized flavonoid; operative interventions for Grade III complications could include hemostatic suturing or topical hemostats.

\section{STUDY BLINDING}

A single surgeon with prior experience in over 100 LHP surgeries and over 70 HAL without doppler previously [19] performed all the cases in this study. Patients and independent observers (dressing clinic staff nurses) who assessed the presence and severity of bleeding) were blinded to the intervention. All patients were assessed in the clinic by the independent observer at 1-day, 1-week and 6-weeks postoperatively.

\section{OUTCOME MEASURES}

The primary outcome measure was overall postoperative bleeding, with sub-analysis at 1-day, 1-week and 6-weeks postoperatively. Severity of bleeding is measured using the verbal rating scale (VRS) where no bleeding $(=0)$, mild bleeding $(=1)$ is defined as minimal trickling or spotting of blood, moderate bleeding $(=2)$ is where the bleeding is manageable with medical treatment, not needing a second procedure to stop the bleeding. Severe bleeding $(=3)$ is defined as significant bleeding causing a drop in hemoglobin level, needing a second operation or procedure to arrest the bleeding. While the extent of intervention for post-operative; haemorrhage was categorized using the Clavien-Dindo Classification [20,21] as detailed in Fig. 2 [22]. Additionally, operating time, presence of perianal swelling were documented and pain was recorded employing the 10-point visual analog scale (VAS) [23].

\section{RANDOMISATION}

Randomization using sealed envelopes in blocks of four was utilized to assign subjects into the two groups (LHP only and LHP with HAL).

\section{SAMPLE SIZE ESTIMATIONS}

To show the effectiveness of supplementation of HAL to LHP in reducing the post-operative bleeding incidence by $20 \%$ [24], we needed to study 35 experimental subjects and 35 control subjects to be able to 
reject the null hypothesis that the failure rate for experimental and control subjects are equal with probability (power) 0.8 . The Type I error probability associated with this test of this null hypothesis is 0.05 . When a $10 \%$ dropout rate was factored in, we needed 38 subjects in each arm. The uncorrected chisquared statistic was employed on the basis of an intention-to-treat model.

\section{STATISTICAL ANALYSIS}

Categorical descriptive data were expressed as number and percentage and continuous descriptive data were expressed as mean \pm standard deviation (SD) unless otherwise stated. Categorical data were analyzed using Chi-square analysis. All continuous variables were tested for normal distribution by the Shapiro-Wilk test. Normally distributed variables were analyzed using Student's T-test. Continuous variables which were not normally distributed were analyzed using the non-parametric Mann-Whitney Utest. A value of $P<0.05$ was considered statistically significant using SPSS version 22.0.

\section{ETHICAL CONSIDERATIONS}

The protocol of the study was registered to Medical Ethics Committee, UMMC, Medical Research and Ethics Committee and ethical approval was obtained from National Medical Research Register (NMRR). NMRR approval was obtained prior to the commencement of the study with the number NMRR-15-111224065 (IIR). The trial was also registered with ClinicalTrials.gov [NCT04667169]. There were no withdrawals or drop-outs from the study.

\section{Results}

\section{CHARACTERISTICS OF STUDY PARTICIPANTS}

A total of 76 patients were recruited for this study. Mean age of the study population was $49.8 \pm 13.8$. There was an almost equal number of males (44.7\%) and females (55.3\%). Ethnic distribution recorded $51.3 \%$ Chinese, $43.4 \%$ Malay, $3.94 \%$ Indian and $1.3 \%$ were foreigners. In regards to the grade of haemorrhoids, most were grade II (52.6\%) and III (46.1\%). The characteristics of patients in both groups were comparable (Table 1). Both groups did not differ statistically in terms of distribution of age, gender, ethnicity and the grades of the haemorrhoids $(P>0.05)$. There was no incidence of primary haemorrhage during surgery. None of the patients was on anticoagulants, nor did they have altered coagulation in their pre-operative assessment. Subjects were discharged on the same day or one day after surgery. 
Table 1

Socio-demographic characteristic and supplementation of haemorrhoidal artery ligation in patients undergoing LHP

\begin{tabular}{|c|c|c|c|}
\hline \multirow[t]{2}{*}{ Socio - Demographic } & LHP & $\mathrm{LHP}+\mathrm{HAL}$ & \multirow[t]{2}{*}{$P$ value } \\
\hline & $\mathrm{n}=38(\%)$ & $n=38(\%)$ & \\
\hline \multicolumn{4}{|l|}{ Gender } \\
\hline Male, $\mathrm{n}=34$ & $20(52.6)$ & $14(36.8)$ & \multirow[t]{2}{*}{$0.166^{\mathrm{a}}$} \\
\hline Female, $n=42$ & $18(47.4)$ & $24(63.2)$ & \\
\hline Age in Years, Mean \pm SD & $49.95 \pm 12.15$ & $49.58 \pm 15.34$ & $0.908^{b}$ \\
\hline \multicolumn{4}{|l|}{ Ethnicity } \\
\hline Malay, $n=33$ & $17(44.7)$ & $16(42.1)$ & $0.235^{a}$ \\
\hline Chinese, $n=39$ & $21(55.3)$ & $18(47.4)$ & \\
\hline Indian, $n=3$ & $0(0.0)$ & $3(7.9)$ & \\
\hline Indonesian, $\mathrm{n}=1$ & $0(0.0)$ & $1(2.6)$ & \\
\hline \multicolumn{4}{|l|}{ Grade of Haemorrhoids } \\
\hline $1(n=1)$ & $0(0.0)$ & $1(2.6)$ & $0.569^{a}$ \\
\hline $2(n=40)$ & $21(55.3)$ & $19(50.0)$ & \\
\hline $3(n=35)$ & 17 (44.7) & 18 (47.4) & \\
\hline
\end{tabular}

\section{POST-OPERATIVE BLEEDING INCIDENCE}

Overall, the LHP group had a bleeding incidence of $23.7 \%$, while the LHP with HAL bleeding incidence was $36.8 \%$. There was a trend in the test group of having higher rates of bleeding but this was not statistically significant. In general, the bleeding incidence was highest at 1-week post-operative period with the incidence of $17.1 \%$. The bleeding incidence at 24 -hours postoperatively was $11.8 \%$, while the incidence decreased to $1.3 \%$ at six weeks post-operation. There was no significant association $(P>0.05)$ found between the presence of bleeding incidence and supplementation of HAL in patients undergoing LHP at 1-Day, 1-Week and 6-Weeks post-operatively (Table 2). 
Table 2

Association of bleeding incidence in supplementation of HAL in patients undergoing LHP

\begin{tabular}{|c|c|c|c|c|}
\hline \multirow[t]{3}{*}{ Bleeding Incidence } & & \multicolumn{2}{|l|}{ Procedure } & \multirow[t]{3}{*}{ P Value } \\
\hline & & \multirow{2}{*}{$\begin{array}{l}\text { LHP } \\
\mathrm{n}=\mathbf{3 8}(\%)\end{array}$} & \multirow{2}{*}{$\begin{array}{l}\text { LHP + HAL } \\
n=38(\%)\end{array}$} & \\
\hline & & & & \\
\hline \multirow[t]{2}{*}{ Overall } & Present & $9(23.7)$ & $14(36.8)$ & \multirow{2}{*}{$0.212^{\mathrm{a}}$} \\
\hline & Absent & $29(76.3)$ & $24(63.2)$ & \\
\hline \multirow[t]{2}{*}{ 1-Day Post-operatively } & Present & $3(7.9)$ & $6(15.8)$ & \multirow{2}{*}{$0.480^{a}$} \\
\hline & Absent & $35(92.1)$ & $32(84.2)$ & \\
\hline \multirow[t]{2}{*}{ 1-Week Post-operatively } & Present & $6(15.8)$ & $7(18.4)$ & \multirow{2}{*}{$0.761^{a}$} \\
\hline & Absent & $32(84.2)$ & $31(81.6)$ & \\
\hline \multirow[t]{2}{*}{ 6-Weeks Post-operatively } & Present & $0(0.0)$ & $1(2.6)$ & \multirow[t]{2}{*}{$1.000^{\mathrm{a}}$} \\
\hline & Absent & $38(100.0)$ & $37(97.4)$ & \\
\hline \multicolumn{5}{|l|}{ Severity } \\
\hline \multicolumn{5}{|l|}{ Presence of Mild Bleeding } \\
\hline 1-Day Post-operatively $(n=9)$ & & $3(7.9)$ & $6(15.8)$ & $0.480^{\mathrm{a}}$ \\
\hline 1-Week Post-operatively $(n=6)$ & & $3(7.9)$ & $3(7.9)$ & $1.000^{\mathrm{a}}$ \\
\hline 6-Weeks Post-operatively $(n=1)$ & & $0(0.0)$ & $1(2.6)$ & $1.000^{\mathrm{a}}$ \\
\hline \multicolumn{5}{|l|}{ Presence of Moderate Bleeding } \\
\hline 1-Day Post-operatively $(n=0)$ & & $0(0.0)$ & $0(0.0)$ & N/A \\
\hline 1-Week Post-operatively $(n=6)$ & & $2(5.3)$ & $4(10.5)$ & $0.674^{\mathrm{a}}$ \\
\hline 6-Weeks Post-operatively $(n=0)$ & & $0(0.0)$ & $0(0.0)$ & $\mathrm{N} / \mathrm{A}$ \\
\hline \multicolumn{5}{|l|}{ Presence of Severe Bleeding } \\
\hline 1-Day Post-operatively $(n=0)$ & & $0(0.0)$ & $0(0.0)$ & $\mathrm{N} / \mathrm{A}$ \\
\hline 1-Week Post-operatively $(n=2)$ & & $1(2.6)$ & $1(2.6)$ & $1.000^{\mathrm{a}}$ \\
\hline 6-Weeks Post-operatively $(n=0)$ & & $0(0.0)$ & $0(0.0)$ & $\mathrm{N} / \mathrm{A}$ \\
\hline
\end{tabular}

\section{SEVERITY OF POSTOPERATIVE BLEEDING}


As expected, clinically significant bleeding overall was more likely to happen within the first postoperative week, as evidenced by the higher VRS score and the extended Clavien-Dindo scale (Table 3). Nevertheless, there was no statistically significant difference between the two groups with respect to severity or timing of bleeding complications. There was no difference in severity of bleeding whether it was scored by extended Clavien-Dindo classification or VRS. Bleeding on the first postoperative day was usually mild (Clavien-Dindo class I). Bleeding incidence was $7.9 \%$ in the LHP group and $15.8 \%$ in the group with HAL supplementation. Significant bleeding as defined by VRS score of 2 and 3 as well as the extended Clavien-Dindo score of II and above was $7.9 \%$ in the LHP only group and $13.2 \%$ in the LHP with HAL group, but this difference was not statistically significant $(P>0.05)$ (Table 3$)$. 
Table 3

Association between Clavien-Dindo Classification and supplementation of HAL in patients undergoing LHP postoperatively

\begin{tabular}{|c|c|c|c|c|}
\hline & & Procedure & & P Value \\
\hline & & LHP & $\mathrm{LHP}+\mathrm{HAL}$ & \\
\hline & & $\mathrm{n}=38(\%)$ & $n=38(\%)$ & \\
\hline 1-Day Post-operatively & & & & \\
\hline Clavien-Dindo Classification & Grade I $(n=9)$ & $3(7.9)$ & $6(15.8)$ & $0.480^{\mathrm{a}}$ \\
\hline & Grade II $(n=0)$ & $0(0.0)$ & $0(0.0)$ & $\mathrm{N} / \mathrm{A}$ \\
\hline & Grade IIIa $(n=0)$ & $0(0.0)$ & $0(0.0)$ & $\mathrm{N} / \mathrm{A}$ \\
\hline & Grade IIIb $(n=0)$ & $0(0.0)$ & $0(0.0)$ & $\mathrm{N} / \mathrm{A}$ \\
\hline & Grade IVa $(n=0)$ & $0(0.0)$ & $0(0.0)$ & $\mathrm{N} / \mathrm{A}$ \\
\hline & Grade IVb $(n=0)$ & $0(0.0)$ & $0(0.0)$ & $\mathrm{N} / \mathrm{A}$ \\
\hline & Grade V $(n=0)$ & $0(0.0)$ & $0(0.0)$ & $\mathrm{N} / \mathrm{A}$ \\
\hline 1-Week Post-operatively & & & & \\
\hline Clavien-Dindo Classification & Grade I $(n=6)$ & $3(7.9)$ & $3(7.9)$ & $1.000^{\mathrm{a}}$ \\
\hline & Grade II $(n=5)$ & $1(2.6)$ & $4(10.5)$ & $0.358^{a}$ \\
\hline & Grade IIIa $(n=2)$ & $2(5.3)$ & $0(0.0)$ & $0.493^{\mathrm{a}}$ \\
\hline & Grade IIIb $(n=1)$ & $0(0.0)$ & $1(2.6)$ & $1.000^{\mathrm{a}}$ \\
\hline & Grade IVa $(n=0)$ & $0(0.0)$ & $0(0.0)$ & $\mathrm{N} / \mathrm{A}$ \\
\hline & Grade IVb $(n=0)$ & $0(0.0)$ & $0(0.0)$ & $\mathrm{N} / \mathrm{A}$ \\
\hline & Grade V $(n=0)$ & $0(0.0)$ & $0(0.0)$ & $\mathrm{N} / \mathrm{A}$ \\
\hline 6-Week Post-operatively & & & & \\
\hline Clavien-Dindo Classification & Grade I $(n=1)$ & $0(0.0)$ & $1(2.6)$ & $1.000^{\mathrm{a}}$ \\
\hline & Grade II $(n=0)$ & $0(0.0)$ & $0(0.0)$ & $\mathrm{N} / \mathrm{A}$ \\
\hline & Grade IIIa $(n=0)$ & $0(0.0)$ & $0(0.0)$ & $\mathrm{N} / \mathrm{A}$ \\
\hline & Grade IIIb $(n=0)$ & $0(0.0)$ & $0(0.0)$ & $\mathrm{N} / \mathrm{A}$ \\
\hline
\end{tabular}




\begin{tabular}{|c|c|c|c|c|}
\hline & & \multicolumn{2}{|l|}{ Procedure } & \multirow[t]{3}{*}{ P Value } \\
\hline & & LHP & $\mathrm{LHP}+\mathrm{HAL}$ & \\
\hline & & $\mathrm{n}=38(\%)$ & $\mathrm{n}=38(\%)$ & \\
\hline & Grade IVa $(n=0)$ & $0(0.0)$ & $0(0.0)$ & N/A \\
\hline & Grade IVb $(n=0)$ & $0(0.0)$ & $0(0.0)$ & N/A \\
\hline & Grade V $(n=0)$ & $0(0.0)$ & $0(0.0)$ & N/A \\
\hline \multicolumn{5}{|c|}{ Significant Bleeding Incidence (VRS 2 and 3 with Clavien-Dindo Grade II and higher) } \\
\hline Present, n (\%) & & $3(7.9)$ & $5(13.2)$ & \multirow[t]{2}{*}{$0.711^{a}$} \\
\hline Absent, n (\%) & & $35(92.1)$ & $33(86.8)$ & \\
\hline \multicolumn{5}{|c|}{$\begin{array}{l}\text { Data are presented as } n(\%) . \text { a }=\text { Chi-square test }(\chi 2) \text {; a p value }<0.05 \text { denotes a statistically significant result; LHP = Laser } \\
\text { haemorrhoidoplasty; HAL = haemorrhoidal artery ligation; verbal rating scale (VRS) }\end{array}$} \\
\hline
\end{tabular}

There was no difference in median operating time in LHP with or without supplementation of HAL (Table 4). 
Table 4

Association between pain score, operative time, presence of swelling with supplementation of HAL in patients undergoing LHP postoperatively

\begin{tabular}{|c|c|c|c|c|}
\hline & & Procedure & & P Value \\
\hline Pain Score, Median (Range) & & LHP & $\mathrm{LHP}+\mathrm{HAL}$ & \\
\hline & & $\mathrm{n}=38$ & $\mathrm{n}=38$ & \\
\hline 1-Day Post-operatively & & $2.00(0.75-3.25)$ & $2.00(1.00-3.25)$ & $0.515^{a}$ \\
\hline 1-Week Post-operatively & & $2.00(0.00-3.00)$ & $2.00(0.00-3.00)$ & $0.768^{a}$ \\
\hline 6-Weeks Post-operatively & & $0.00(0.00-0.00)$ & $0.00(0.00-0.00)$ & $0.945^{a}$ \\
\hline Operation Time in Minutes, & (Range) & $25(20-30)$ & $25(20-30)$ & $0.107^{a}$ \\
\hline Presence of Swelling, $n$ (\%) & & & & \\
\hline 1-Day Post-operatively & Present & $14(36.8)$ & $12(31.6)$ & $0.629^{b}$ \\
\hline & Absent & $24(63.2)$ & $26(68.4)$ & \\
\hline 1-Week Post-operatively & Present & $8(24.1)$ & $6(21.1)$ & $0.554^{b}$ \\
\hline & Absent & $30(75.9)$ & $32(78.9)$ & \\
\hline 6-Weeks Post-operatively & Present & $4(10.5)$ & $2(5.3)$ & $0.674^{b}$ \\
\hline & Absent & $34(89.5)$ & $36(94.7)$ & \\
\hline
\end{tabular}

\section{PERIANAL SWELLING}

Perianal swelling was most pronounced in both groups on the first postoperative day, with an incidence of $36.8 \%$ in the LHP group versus $31.6 \%$ in the LHP + HAL group. This was not statistically significant (P $>0.05$ ) (Table 4).

\section{PAIN SCORE}

The median pain score by VAS for both groups were the same i.e., 2.00 at 1-Day and 1-Week after surgery, and 0.00 at 6 -Weeks after surgery. No patients in the study required additional oral or parenteral analgesia. In Table 4, there was no significant association $(P>0.05)$ found between pain score and supplementation of HAL in

patients undergoing LHP at 1-Day, 1-Week and 6-Weeks post-operatively.

\section{Discussion}


Postoperative bleeding is a common and troublesome complication after hemorrhoidal surgery; thus, it is important to incorporate interventions with proven benefit in this regard. It was anticipated that the addition of HAL to LHP would be beneficial by lowering the incidence of postoperative bleeding, and thus reducing patient morbidity while increasing patient satisfaction.

Interestingly, our results did not show an advantage for the addition of HAL to LHP in decreasing the incidence of postoperative bleeding; in fact, there was a trend in the opposite direction, although not statistically significant. Although in principle HAL may seemingly reduce postoperative bleeding rates by dearterialization (i.e., by suture ligation) of the hemorrhoidal arteries [11, 12], this did not translate into clinical outcomes. This may be because LHP already coagulates the same vasculature by virtue of the laser ablation [25]. Furthermore, these are consistent with some developmental theories of haemorrhoids [26] and with the postulations that all dearterialization techniques have the advantage of preserving the anatomy and physiology of the anal canal [27]. In addition, the application of suture ligation creates additional sites for bleeding at the point of needle entry.

Most post-operative bleeding occurred within the first week, was mild and resolved spontaneously. The timing of bleeding after haemorrhoid surgery can be generally divided into immediate and delayed. Immediate bleeding is described as bleeding occurring within the first 48 hours of a procedure. The mechanism behind immediate bleeding is probably related to the loss of control of the vascular pedicle. Delayed bleeding, on the other hand, is defined as per rectal bleeding up to two weeks following the procedure which is more likely due local trauma or infection $[5,28]$. Additionally, delayed bleeding may be influenced by postoperative analgesia especially when NSAIDS are being prescribed which can increase the incidence of bleeding [29].

This study revealed that postoperative bleeding rarely occurred in the post-operative period of six weeks. This phenomenon may be explained by the mechanism of action of the laser ablation itself. LHP results in gradual fibrosis of the hemorrhoidal tissue over a period of four to six weeks. Hence, most of the postoperative bleeding, if any, would naturally occur prior to this period. Fortunately, most per rectal bleeding following haemorrhoid surgery will resolve spontaneously. For those that do not, treatment would depend on two factors; the location of the bleeding and the degree of blood loss. External measures such as tamponade or compression with gauze or suture ligation at the bedside are usually successful in arresting the bleeding. Injection of local anaesthetic with adrenaline can also be performed at the bedside with a good success rate although such bedside procedures may be uncomfortable for the patient. Up to 15 to $33 \%$ of patients with bleeding after haemorrhoid surgery would be required for a re-operation [ 30 , 31].

It is known that stapled haemorrhoidopexy has a higher re-bleeding rate compared to excisional haemorrhoidectomy with rates over 30\% [32]. Surprisingly, most of the re-bleeding cases will not have an identifiable source of bleeding by the time they are examined in the operating room and more often than not, a sponge or tamponade will just be placed in the anal canal. However, these significant bleeding episodes may even be recurrent and cause distress to both the patient and the surgeon [31] Here only a 
small percentage $(2.63 \%)$ of re-bleeding patients needed a second procedure or operation to arrest the bleeding; i.e., two cases, one per group were re-admitted. These results are comparable to studies on postoperative bleeding in LHP in other centres $[1,5,11,33]$.

Despite the addition of HAL to the LHP, there was no significant difference in the operation time in both groups. This may be explained by the fact that the study was conducted in a colorectal centre, and the surgeons were familiar with both techniques. Hypothetically, if the procedure is performed by inexperienced surgeons, additional procedures on top of LHP may significantly prolong the operating time [34]. Furthermore, an additional (but unnecessary) procedure may pose an increased risk of complications for the patient. Although most trials involving HAL were associated with a low re-bleeding rate, one study has been shown to have a postoperative bleeding rate of as high as $70 \%$ [18].

Perianal swelling was also completely resolved by the end of six weeks of surgery. In regards to the pain score (VAS), there was no clinical or statistically significant difference in between both groups since both LHP and HAL are minimally invasive procedures and non-excisional in nature [4-6]. In fact, most patients only experienced mild pain (median pain score $=$ " $2.00 "$ ) which were easily controlled with oral paracetamol and celecoxib.

\section{Study Limitations}

There were no prior studies looking into the bleeding rate for LHP with HAL, therefore the sample size for this study was calculated based on a surrogate bleeding rate from HAL from another study model. This study design focused on a short-term follow-up at a single-centre only. Larger randomized trials are awaited to demonstrate the bleeding incidence, long-term outcomes (up to 2 years) and efficacy of combined LHP procedures is warranted.

\section{Conclusion}

Supplementation of HAL to LHP does not decrease the post-operative bleeding incidence.

\section{Abbreviations}

HAL

hemorrhoidal artery ligation

LHP

laser hemorrhoidoplasty

\section{Declarations}

AUTHORS' CONTRIBUTIONS 
Conceptualization: ACR, SYL, Methodology: ACR, SYL; Formal analysis and investigation: SYL, RR, Writing - original draft preparation: SYL, RR, ACR; Writing - review and editing: RR, ACR; Resources: SYL, ACR; Supervision: ACR.

Acknowledgments: The authors would like to thank Dr. Lim Hiong Chin and Dr. Mohamed Rezal Bin Abdul Aziz from Department of Surgery, Faculty of Medicine, University of Malaya for accrual of subjects.

Funding/Support: None

Financial Disclaimers: No grant or financial relationship

Conflicts of Interest/ Competing Interest: None. All Authors declare not to have any conflict of interest Availability of data and material: Not applicable

Code Availability: Not applicable

Ethics Approvals: Ethical approval was obtained from National Medical Research Register (NMRR) prior to the commencement of the study with the number NMRR-15-1112-24065 (IIR).

Trial Registration: ClinicalTrials.gov [NCT04667169].

Consent to participate: Informed consent forms were signed by all patients as per ethical approval guidelines.

Consent for publication: This work consent has been obtained and authors approve the final version of the manuscript.

\section{References}

1. Ganz RA. The evaluation and treatment of haemorrhoids: a guide for the gastroenterologist. Clin Gastroenterol hepatology: official Clin Pract J Am Gastroenterological Association. 2013;11(6):593603. doi:10.1016/j.cgh.2012.12.020.

2. Sandler RS, Peery AF. Rethinking What We Know About Hemorrhoids. Clinical gastroenterology and hepatology: the official clinical practice. J Am Gastroenterological Association. 2019;17(1):8-15. doi:10.1016/j.cgh.2018.03.020.

3. Lohsiriwat V. Treatment of haemorrhoids: A coloproctologist's view. World J Gastroenterol. 2015;21(31):9245-52. doi:10.3748/wjg.v21.i31.9245.

4. UI Ain Q, Bashir Y, Eguare E. Evaluation of the effectiveness and patients' contentment with transanal haemorrhoidal artery dearterialisation and mucopexy (THD) for treatment of haemorrhoidal disease: a 6-year study. Ir J Med Sci. 2018;187(3):647-55. doi:10.1007/s11845-017-1715-8.

5. MacRae HM, McLeod RS. Comparison of hemorrhoidal treatments: a meta-analysis. Can J Surg J canadien de chirurgie. 1997;40(1):14-7. 
6. Longchamp G, Liot E, Meyer J, Toso C, Buchs NC, Ris F. Non-excisional laser therapies for hemorrhoidal disease: a systematic review of the literature. Lasers Med Sci. 2021;36(3):485-96. doi:10.1007/s10103-020-03142-8.

7. Gallo G, Martellucci J, Sturiale A, Clerico G, Milito G, Marino F, Cocorullo G, Giordano P, Mistrangelo M, Trompetto M. Consensus statement of the Italian society of colorectal surgery (SICCR): management and treatment of hemorrhoidal disease. Tech Coloproctol. 2020;24(2):145-64. doi:10.1007/s10151020-02149-1.

8. Won LS, Real LK, Yean HD. The Efficacy of a Nd:YAG Laser in a Hemorrhoidectomy. J Korean Soc Coloproctol. 1999;15(3):203-8.

9. Weyand G, Theis CS, Fofana AN, Rudiger F, Gehrke T. [Laserhemorrhoidoplasty with $1470 \mathrm{~nm}$ Diode Laser in the Treatment of Second to Fourth Degree Hemorrhoidal Disease - a Cohort Study with 497 Patients]. Zentralbl Chir. 2019;144(4):355-63. doi:10.1055/s-0043-120449.

10. Plapler H, Hage R, Duarte J, Lopes N, Masson I, Cazarini C, Fukuda T. (2009) A new method for haemorrhoid surgery: intrahemorrhoidal diode laser, does it work? Photomedicine and laser surgery 27 (5):819-823. doi:10.1089/pho.2008.2368.

11. Gupta PJ, Kalaskar S, Taori S, Heda PS. Doppler-guided hemorrhoidal artery ligation does not offer any advantage over suture ligation of grade 3 symptomatic haemorrhoids. Tech Coloproctol. 2011;15(4):439-44. doi:10.1007/s10151-011-0780-7.

12. Avital S, Inbar R, Karin E, Greenberg R. Is Doppler ultrasonography essential for hemorrhoidal artery ligation? Tech Coloproctol. 2012;16(4):291-4. doi:10.1007/s10151-012-0844-3.

13. Ng KS, Holzgang M, Young C. Still a Case of "No Pain, No Gain"? An Updated and Critical Review of the Pathogenesis, Diagnosis, and Management Options for Hemorrhoids in 2020. Ann Coloproctol. 2020;36(3):133-47. doi:10.3393/ac.2020.05.04.

14. Eskandaros M, Darwish A. Comparative study between Milligan-Morgan hemorrhoidectomy, stapled hemorrhoidopexy, and laser hemorrhoidoplasty in patients with third degree haemorrhoids: a prospective study. Egypt J Surg. 2020;39(2):352-63. doi:10.4103/ejs.ejs_214_19.

15. Poskus T, Danys D, Makunaite G, Mainelis A, Mikalauskas S, Poskus E, Jotautas V, Dulskas A, Jasiunas E, Strupas K. Results of the double-blind randomized controlled trial comparing laser hemorrhoidoplasty with sutured mucopexy and excisional hemorrhoidectomy. Int J Colorectal Dis. 2020;35(3):481-90. doi:10.1007/s00384-019-03460-6.

16. Qamar Naqvi SR, Qamar Naqvi SS, Rashid MM, Sheikh IA, Ali M, Nafees AUA. Haemorrhoidal Artery Ligation Operation Without Doppler Guidance. J Ayub Med Coll Abbottabad. 2018;30(Suppl 1): (4):S664-s667.

17. Ramirez JM, Aguilella V, Elia M, Gracia JA, Martinez M. (2005) Doppler-guided hemorrhoidal artery ligation in the management of symptomatic haemorrhoids. Revista espanola de enfermedades digestivas: organo oficial de la Sociedad Espanola de Patologia Digestiva 97 (2):97-103. doi:10.4321/s1130-01082005000200004. 
18. Nikam V, Deshpande A, Chandorkar I, Sahoo S. (2018) A prospective study of efficacy and safety of rubber band ligation in the treatment of Grade II and III haemorrhoids - a western Indian experience. J Coloproctology 38. doi:10.1016/j.jcol.2018.03.006.

19. Chong HY, Roslani AC, Rajandram R, Kumar S, Malik AA, Law CW, Rajasingam V, Kasipillai J. (2022) Clinical short-term outcomes of laser hemorrhoidplasty: a multicenter study Journal of Health and Translational Medicine (JUMMEC) in press.

20. De Nardi P, Tamburini AM, Gazzetta PG, Lemma M, Pascariello A, Asteria CR. Hemorrhoid laser procedure for second- and third-degree haemorrhoids: results from a multicenter prospective study. Tech Coloproctol. 2016;20(7):455-9. doi:10.1007/s10151-016-1479-6.

21. Giamundo P, Braini A, Calabro G, Crea N, De Nardi P, Fabiano F, Lippa M, Mastromarino A, Tamburini AM. Doppler-guided hemorrhoidal dearterialization with laser (HeLP): indications and clinical outcome in the long-term. Results of a multicenter trial. Surg Endosc. 2021. doi:10.1007/s00464-02008248-2.

22. Katayama H, Kurokawa Y, Nakamura K, Ito H, Kanemitsu Y, Masuda N, Tsubosa Y, Satoh T, Yokomizo A, Fukuda H, Sasako M. Extended Clavien-Dindo classification of surgical complications: Japan Clinical Oncology Group postoperative complications criteria. Surg Today. 2016;46(6):668-85. doi:10.1007/s00595-015-1236-x.

23. Maloku H, Gashi Z, Lazovic R, Islami H, Juniku-Shkololli A. Laser Hemorrhoidoplasty Procedure vs Open Surgical Hemorrhoidectomy: a Trial Comparing 2 Treatments for Hemorrhoids of Third and Fourth Degree. Acta Inf Med. 2014;22(6):365-7. doi:10.5455/aim.2014.22.365-367.

24. Song $Y$, Chen $H$, Yang F, Zeng $Y, H e ~ Y$, Huang $H$. Transanal hemorrhoidal dearterialization versus stapled hemorrhoidectomy in the treatment of haemorrhoids: A PRISMA-compliant updated metaanalysis of randomized control trials. Med (Baltim). 2018;97(29):e11502. doi:10.1097/MD.0000000000011502.

25. Danys D, Pacevicius J, Makunaite G, Palubeckas R, Mainelis A, Markevicius N, Strupas K, Poskus T. Tissue Coagulation in Laser Hemorrhoidoplasty - An Experimental Study. Open Med (Wars). 2020;15:185-9. doi:10.1515/med-2020-0027.

26. Margetis N. Pathophysiology of internal haemorrhoids. Ann Gastroenterol. 2019;32(3):264-72. doi:10.20524/aog.2019.0355.

27. Giamundo P. Advantages and limits of hemorrhoidal dearterialization in the treatment of symptomatic haemorrhoids. World J Gastrointest Surg. 2016;8(1):1-4. doi:10.4240/wjgs.v8.i1.1.

28. Rosen L, Sipe P, Stasik JJ, Riether RD, Trimpi HD. Outcome of delayed haemorrhage following surgical hemorrhoidectomy. Dis Colon Rectum. 1993;36(8):743-6. doi:10.1007/bf02048364.

29. Place RJ, Coloma M, White PF, Huber PJ, Van Vlymen J, Simmang CL. Ketorolac improves recovery after outpatient anorectal surgery. Dis Colon Rectum. 2000;43(6):804-8. doi:10.1007/bf02238018.

30. Chen HH, Wang JY, Changchien CR, Yeh CY, Tsai WS, Tang R. Effective management of posthemorrhoidectomy secondary haemorrhage using rectal irrigation. Dis Colon Rectum. 2002;45(2):234-8. doi:10.1007/s10350-004-6154-8. 
31. Nisar PJ, Acheson AG, Neal KR, Scholefield JH. Stapled hemorrhoidopexy compared with conventional hemorrhoidectomy: systematic review of randomized, controlled trials. Dis Colon Rectum. 2004;47(11):1837-45. doi:10.1007/s10350-004-0679-8.

32. Porrett LJ, Porrett JK, Ho YH. Documented complications of staple hemorrhoidopexy: a systematic review. Int Surg. 2015;100(1):44-57. doi:10.9738/INTSURG-D-13-00173.1.

33. Béliard A, Labbé F, de Faucal D, Fabreguette JM, Pouderoux P, Borie F. A prospective and comparative study between stapled hemorrhoidopexy and hemorrhoidal artery ligation with mucopexy. J Visc Surg. 2014;151(4):257-62. doi:10.1016/j.jviscsurg.2014.03.009.

34. Hopper AN, Jamison MH, Lewis WG. Learning curves in surgical practice. Postgrad Med J. 2007;83(986):777-9. doi:10.1136/pgmj.2007.057190.

\section{Figures}

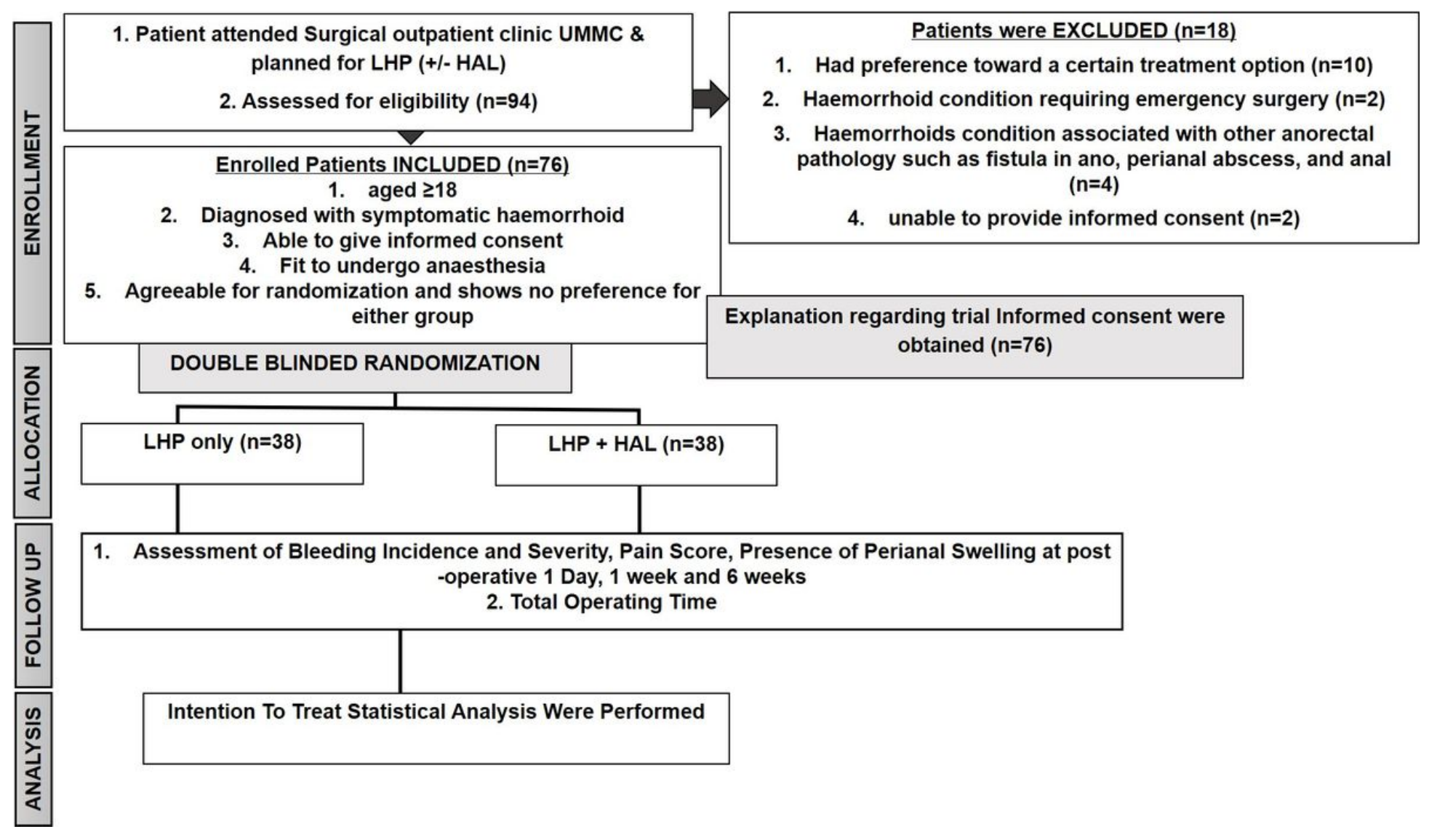

\section{Figure 1}

The Randomized Control Trial Consort Diagram 


\section{Principle of grading}

\begin{tabular}{cccccccc}
\hline I & II & IIIa & IIIb & IVa & IVb & V & $\begin{array}{l}\text { Supplemental } \\
\text { explanation } \\
\text { of suffix “d" }\end{array}$ \\
\hline
\end{tabular}

\begin{tabular}{|c|c|c|c|c|c|c|c|c|}
\hline $\begin{array}{l}\text { Postoperative } \\
\text { Haemorrhage }\end{array}$ & $\begin{array}{l}\text { Controllable } \\
\text { with } \\
\text { compression } \\
\text { only }\end{array}$ & $\begin{array}{l}\text { Blood } \\
\text { transfusion } \\
\text { or medical } \\
\text { management } \\
\text { indicated }\end{array}$ & $\begin{array}{l}\text { Surgical } \\
\text { hemostasis } \\
\text { under local } \\
\text { anesthesia } \\
\text { or } \\
\text { endoscopic } \\
\text { and } \\
\text { radiological } \\
\text { intervention } \\
\text { hemostasis } \\
\text { indicated }\end{array}$ & $\begin{array}{l}\text { Intervention } \\
\text { under } \\
\text { general } \\
\text { anesthesia } \\
\text { indicated } \\
\text { (hemostasis) }\end{array}$ & $\begin{array}{l}\text { Single organ } \\
\text { failure; } \\
\text { stepdown } \\
\text { IC/ICU } \\
\text { management } \\
\text { indicated }\end{array}$ & $\begin{array}{l}\text { Multiple } \\
\text { organ failure; } \\
\text { IC/ICU } \\
\text { management } \\
\text { indicated }\end{array}$ & Death & $\begin{array}{l}\text { Persistent } \\
\text { anemia }\end{array}$ \\
\hline
\end{tabular}

Figure 2

Grading of the extended Clavien-Dindo classification for post-operative haemorrhage [7]

\section{Supplementary Files}

This is a list of supplementary files associated with this preprint. Click to download.

- SPIRITChecklistBMJSACRsubmission.doc 